Sharif University of Technology
Scientia Iranica
SCIENTIA
IRANICA
Transtions A: Civil Engineering
www.scientiairanica.com

\title{
Performance evaluation of curved welded flange-plate beam-to-column connections
}

\author{
Y. Ghafari, M. Mofid* and O. Sedehi \\ Department of Civil Engineering, Sharif University of Technology, Tehran, P.O. Box 11155-8639, Iran.
}

Received 2 February 2015; received in revised form 11 August 2015; accepted 8 December 2015

\author{
KEYWORDS \\ Curved flange-plate; \\ Beam-to-column \\ connections; \\ Semi-rigid \\ connections; \\ Moment-rotation \\ behavior; \\ Theoretical approach; \\ Finite element \\ analysis; \\ Plastic hinge.
}

\begin{abstract}
In this paper, curved welded flange-plate beam-to-column connections are introduced and investigated analytically. The connection is comprised of two curved flange-plates installed on beam flange to transfer bending moment and two web angles for transmission of shear forces. Theoretical relationships are established for initial stiffness, ultimate moment, and ultimate rotation to be used for calibration of a bilinear model of moment-rotation. Furthermore, finite element analyses are conducted on eighteen specimens designed based upon the results of theoretical study. Analyses are in good agreement with theories verifying modeling procedure. Block shear rupture, tension rupture, and formation of three plastic hinges in semi-circular portion of the flange-plate are identified as the major failure modes. The failure due to formation of three plastic hinges in the flange-plate is suggested to govern the connection design, which leads to a ductile behavior. As a result, a flow chart is suggested to design the proposed connection.

(C) 2016 Sharif University of Technology. All rights reserved.
\end{abstract}

\section{Introduction}

Ductile performance of steel beam-to-column connections has stepped into spotlight in the last two decades, especially after the 1994 Northridge earthquake. Previous studies on semi-rigid connections revealed that moment-resisting frames with similar connections attract lower inertia forces, which might be attributed to flexible behavior of connections [13]. Moreover, semi-rigid connections mostly exhibit a ductile behavior in comparison with similar rigid connections [4-8]. Frames with semi-rigid connections usually represent stable hysteretic responses under seismic excitations [1]. In addition, using semi-rigid connections reduces the beam moment transferred to the column, which prohibits the probable failure in column resulting in improvement of overall stability of

*. Corresponding author. Tel: +982166164214

E-mail addresses: ghafari-yusef@outlook.com (Y. Ghafari); mofid@sharif.edu (M. Mofid); sedehi-omid@outlook.com (O. Sedehi) the structure [7-8]. Consequently, various semi-rigid connections have been proposed and studied in both experiments and analyses leading to allowance of using semi-rigid connections [9-11].

In general perspective, beam-to-column connections are usually studied with three conventional approaches, including experimental investigations, Finite Element (FE) analyses, and theoretical studies. Experiments were usually conducted for various reasons such as investigation of the overall behavior, development of practical relationships, and preparation of verified results for further analytical studies. However, internal forces and stresses cannot be easily detected in experiments, which have encouraged investigators to use FE simulations and theoretical approaches [12-13]. Therefore, a procedure was established among numerous investigators, which analytical and theoretical approaches were usually calibrated and verified according to a few test specimens [1214]. Repetitive application of this procedure has promoted this attitude that application of FE analyses together with previously accepted theories can 
provide satisfactory results; thus, experiments can be avoided [14].

Nonlinear behavior of beam-to-column connections plays an important role to achieve acceptable results in macro-modeling of steel structures [15]. To account for connection flexibility, moment-rotation behavior of the connections is usually introduced into the frame joints [14-17]. Moment-rotation curves were usually expressed in terms of geometric and material properties. In this particular area of research, theoretical studies are proved to be helpful and are used frequently [17].

In this paper, a new semi-rigid beam-to-column connection denominated as curved welded flange-plate connection is proposed and studied analytically. A previously verified theoretical approach is applied for performance evaluation of the connections subjected to bending moment. Subsequently, closed-form relationships for initial stiffness, ultimate moment, and ultimate rotation are established to be utilized for calibration of a bilinear model of moment-rotation. This model is used for verification and development of FE models.

\section{Curved welded flange-plate connection}

Curved welded flange-plate beam-to-column connections are basically similar to conventional flange-plate connections aimed at suggesting a new semi-rigid connection. Figure 1(a) depicts the overall configuration of the connection. As shown, web angles connected with fillet welds transfer beam shear force to the column. Moreover, curved flange-plates are connected with Complete Joint Penetration (CJP) groove welds to the column flange aimed at providing required flexural strength. Fillet welds connect flange-plate to the beam flange. Transverse stiffeners are placed and connected with fillet welds to prevent web local crippling and yielding. The main purpose of using the curved plates is improvement of dissipated energy and rotation capacity. In other words, semi-circular portion of the flange-plate is expected to achieve sufficient level of deformation capacity.

In practice, the flange-plate can be fabricated by bending the plate, which might induce some stress concentration. Hence, we suggest an alternative method for fabricating the plate from a pipe and a plate connected with full penetration groove welds. Figure 1(b) clearly shows fabrication of the flange-plate by this method. It is worth noting that a cold cutter can separate the semi-circular part from a seamless rolled pipe, which prevents formation of residual stress and strain. For this purpose, pre-heating of the groove welds might be helpful as well.

\section{Theoretical study}

Theoretical approaches have been used for the assessment of overall behavior of beam-to-column connections, especially for calibration of moment-rotation curves [14]. In this paper, a bilinear model is considered for predicting the moment-rotation behavior. Figure 2 illustrates model parameters, where $K_{i}, K_{p}, M_{y}, M_{u}$, $\theta_{y}$, and $\theta_{u}$ denote initial stiffness, inelastic stiffness, yield moment, the ultimate moment, yield rotation, and the ultimate rotation, respectively. For calibration
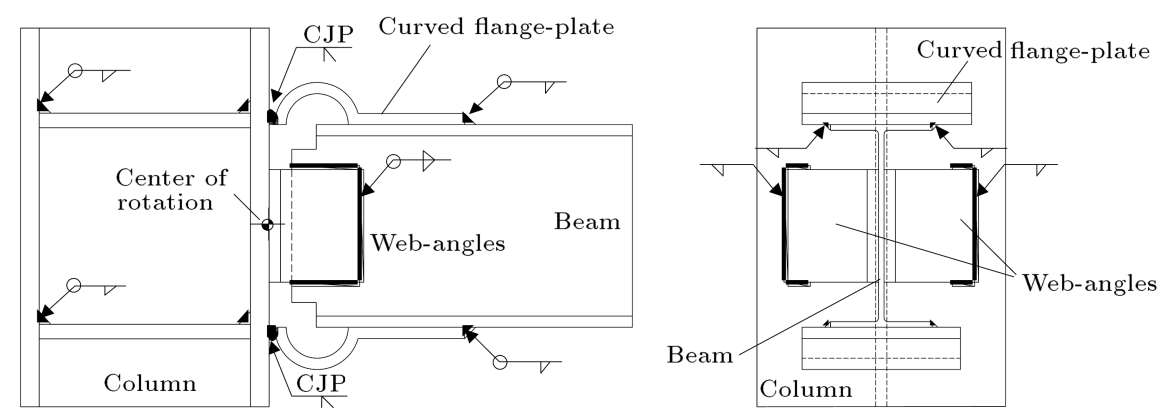

(a)
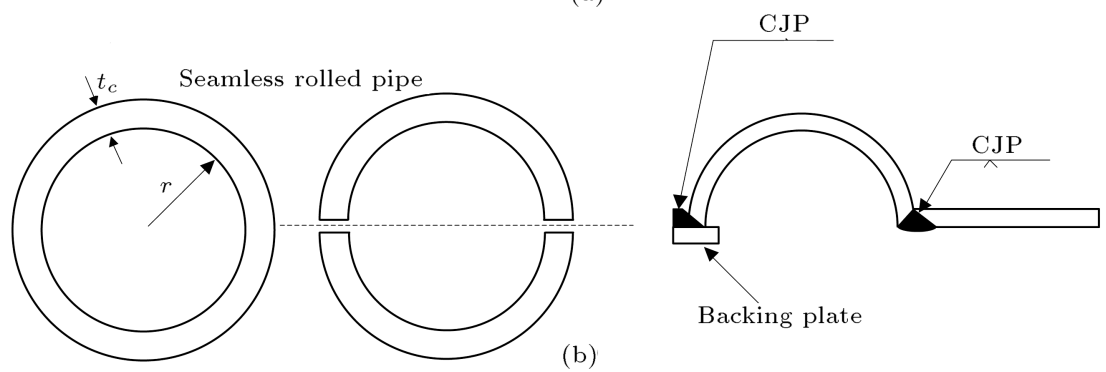

(b)

Figure 1. (a) Curved welded flange-plate connections with double web angle. (b) Fabrication of curved elements from a seamless pipe. 


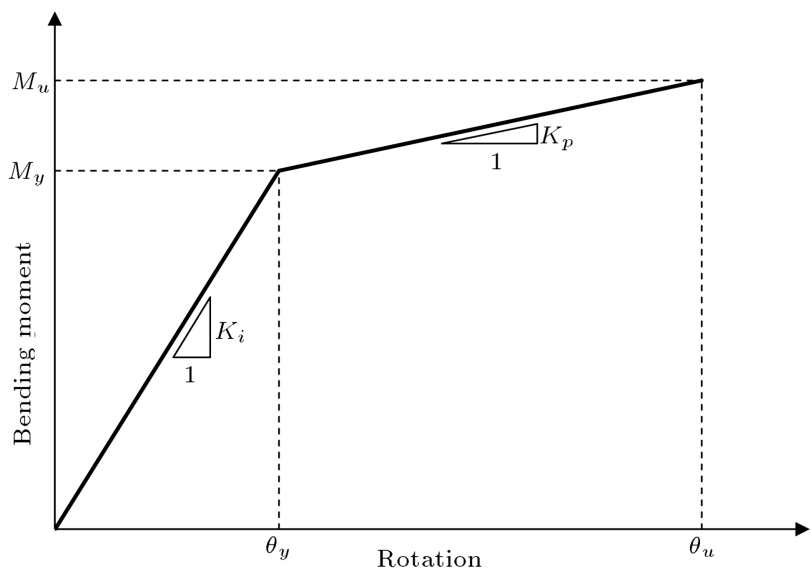

Figure 2. Bilinear moment-rotation model suggested for the connection.

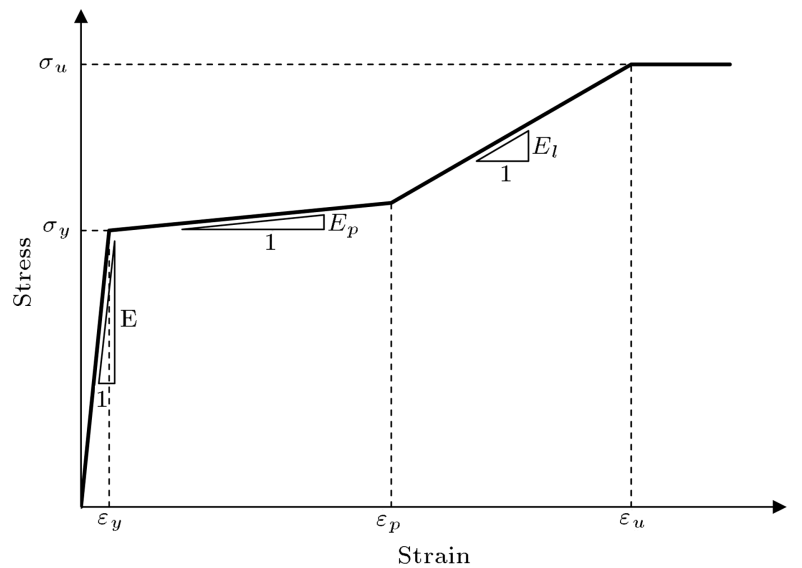

Figure 3. Stress-strain model for structural steel used by Mohamadi-Shooreh and Mofid [16].

of this model, the following assumptions were made:

- Material behavior was expressed by the multi-linear model suggested by Mohamadi-Shooreh and Mofid [16] for structural steel shown in Figure 3;

- Behavior of flange-plates in tension and compression were assumed to be similar;

- Overall rotation of the connection was determined from the relative rotation between beam and column;

- Center of rotation is considered on the longitudinal axis of the beam located on the exterior face of column flange, as shown in Figure 1(a). This assumption has been previously used for web-angle connections by Lee and Moon [15];

- Effects of out-of-plane deformations on the overall rotation and stiffness were neglected.

\subsection{Evaluation of stiffness}

Elastic stiffness of connections can be explained in terms of geometric properties together with the elastic behavior of the material. In previous studies [1417], basic principles of elasticity theory were used to establish a general procedure for evaluation of initial stiffness. The following steps should be taken to apply this procedure:

- Identification of effective elements in overall behavior;

- Replacing effective elements with appropriate springs;

- Calculation of springs stiffness based on the elasticity theory;

- Simplification of the behavior as a combined action of parallel and series springs;

- Calculation of the equivalent stiffness as an estimate for the initial stiffness.

In the case of the aforementioned connection, flange-plates and web angles are the major elements that significantly affect stiffness, which should be replaced by springs based on their performance. The plates were replaced by two translational springs, and double-web angle was replaced by a torsional spring, as shown in Figure 4(a). The theoretical approach should be applied to determine the stiffness.
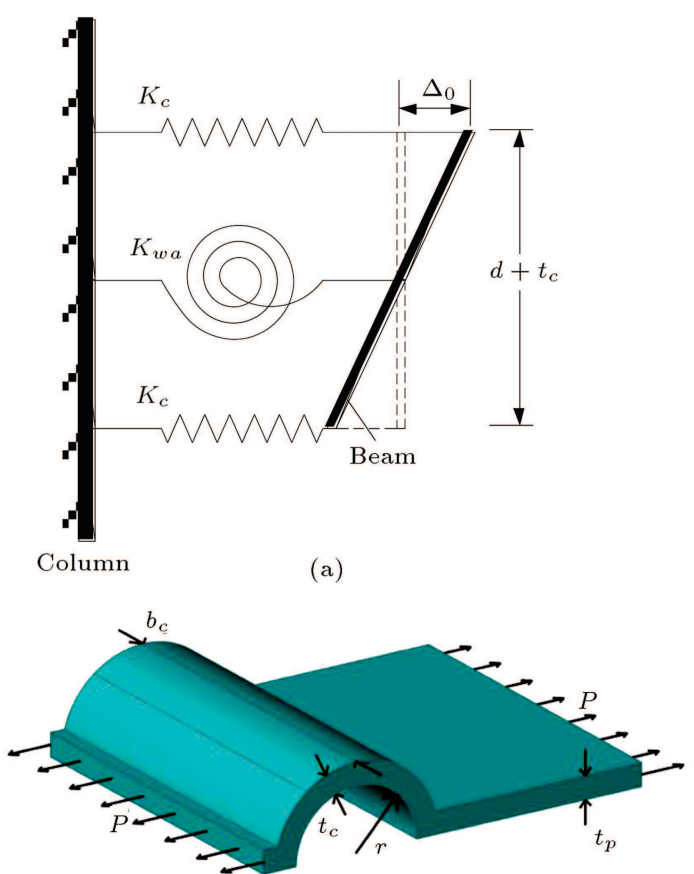

(b)

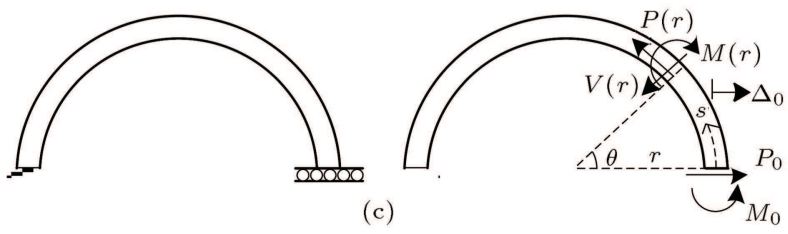

Figure 4. (a) Simplification of the connection behavior by the method of spring replacement. (b) Applied forces to the flange-plate. (c) Internal forces of semi-circular portion. 
The flange-plates are fixed at the both ends; one end is connected to the beam flange with fillet welds and the other end is connected to the column flange with groove welds. In general, the flange-plates are subject to axial loads, as illustrated in Figure 4(b). However, the semi-circular portion of the flange-plate undergoes a combination of flexure, shear, and axial forces, which triggers a specific failure mechanism. The principle of minimum total potential energy was adopted for calculation of flange-plate stiffness. As indicated in Eq. (1), the total potential energy for the semi-circular portion can be explained in terms of the external energy and the internally stored flexural, shear, and axial energies:

$$
\Pi=\int \frac{M^{2}(r)}{2 E I} d s+\int \frac{P^{2}(r)}{2 E A} d s+\int \frac{V^{2}(r)}{2 \alpha G A} d s-P_{0} \cdot \Delta_{0},
$$

where $\Pi$ is total energy; $M(r), P(r)$, and $V(r)$ are internal bending moment, axial force, and shear force, respectively, as shown in Figure 4(c); $E$ is modulus of elasticity, $G$ is shear modulus taken equal to $E / 2(1+v)$, in which $v$ denotes poisson's ratio; $I$ is the second moment of inertia; $A$ is cross sectional area; and $\alpha$ is considered as $5 / 6$ for rectangular cross section; $P_{0}$ and $\Delta_{0}$ are force and displacement at the end of the semicircular portion shown in Figure 4(c). Equilibrium equations for the internal bending moment, the axial force, and the shear force will result in the following equations:

$$
\begin{aligned}
& M(r)=P_{0} \cdot r \cdot \sin (\theta)-M_{0}, \\
& P(r)=P_{0} \sin (\theta), \\
& V(r)=P_{0} \cos (\theta),
\end{aligned}
$$

where $r$ is radius of semi-circular portion illustrated in Figure $4(\mathrm{~b})$, and $M_{0}$ is end moment. These equations are replaced into Eq. (1), which results in the following equation:

$$
\begin{aligned}
\Pi= & \int \frac{\left(P_{0} \cdot r \cdot \sin (\theta)-M_{0}\right)^{2}}{2 E I} d s+\int \frac{\left(P_{0} \sin (\theta)\right)^{2}}{2 E A} d s \\
& +\int \frac{\left(P_{0} \cos (\theta)\right)^{2}}{2 \alpha G A} d s-P_{0} \cdot \Delta_{0} .
\end{aligned}
$$

According to the principle of minimum potential energy, total potential energy $(\Pi)$ should be minimized to achieve the most stable condition. Thus, the variation of total energy $(\Pi)$ is zero, which can be written in the following form:

$$
D \Pi=0 \Longleftrightarrow \frac{\partial \Pi}{\partial M_{0}} d M_{0}+\frac{\partial \Pi}{\partial P_{0}} d P_{0}=0 .
$$

In order to satisfy this equation, partial differentials of total potential energy with respect to the end moment $\left(M_{0}\right)$ and the applied force $\left(P_{0}\right)$ must be zero, as written:

$$
\frac{\partial \Pi}{\partial P_{0}}=0, \quad \frac{\partial \Pi}{\partial M_{0}}=0 .
$$

From these equations and Eq. (3), we arrive at:

$$
\left\{\begin{array}{l}
2 \int_{0}^{\pi / 2} \frac{-\left(P_{0} \cdot r \sin (\theta)-M_{0}\right)}{E I} r d \theta=0 \\
2 \int_{0}^{\pi / 2} \frac{r \sin (\theta)\left(P_{0} \cdot r \sin (\theta)-M_{0}\right)}{E I} r d \theta+2 \int_{0}^{\pi / 2} \frac{P_{0} \sin ^{2}(\theta)}{E A} r d \theta \\
\quad+2 \int_{0}^{\pi / 2} \frac{P_{0} \cos ^{2}(\theta)}{\alpha G A} r d \theta-\Delta_{0}=0
\end{array}\right.
$$

where $M_{o}$ and $\Delta_{0}$ are variables that should be found from these equations. Subsequently, integration was conducted, and an estimation of the elastic stiffness of the curved plate was obtained as follows:

$$
K_{e}=\frac{P_{0}}{\Delta_{0}}=\frac{E I}{r}\left\{\left(\frac{\pi^{2}-8}{2 \pi}\right) r^{2}+\frac{\pi}{2 \alpha A / I}(2+2 v+\alpha)\right\}_{(4)}^{-1}
$$

As discussed, web angles were replaced by a torsional spring. Theoretical formulations for the initial stiffness of web angles had been developed previously [18-19]. Figure 5(a) illustrates the overall behavior of web angles along with a simplified model. For the sake

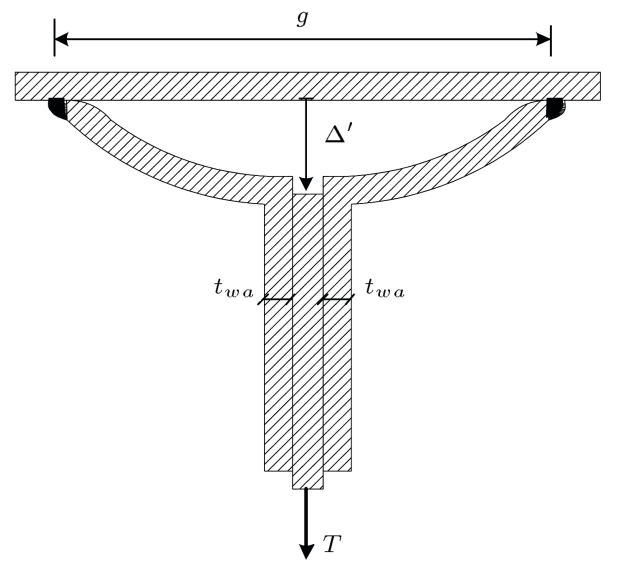

(a)

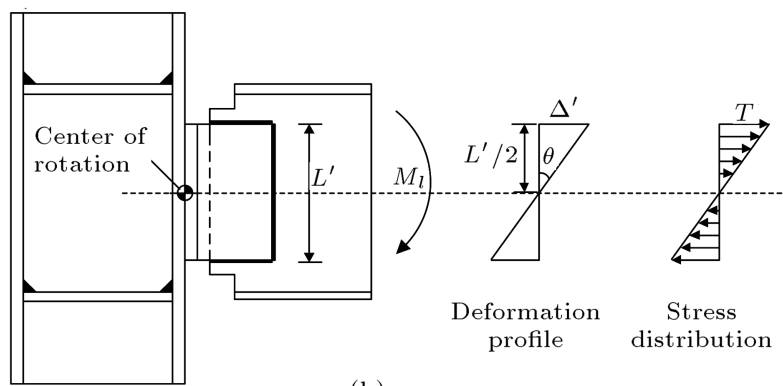

(b)

Figure 5. (a) Overall behavior of the web angles [18]. (b) Deformation profile and stress distribution in the web angles [15]. 
of simplicity, a linear loading pattern was considered as the deformation profile shown in Figure 5(b). Web angles could be replaced by a simply-supported beam subjected to a bending moment. Hence, transferred load from the beam to the web angles $(T)$ can be written in terms of bending moment $\left(M_{1}\right)$ and angle length $\left(L^{\prime}\right)$ as follows:

$$
T=\frac{6 M_{1}}{\left(L^{\prime}\right)^{2}} \text {. }
$$

In reference to Figure 5(a), overall rotation of double angle can be explained in terms of the uppermost midspan deflection $\left(\Delta^{\prime}\right)$ and half of the angle length $\left(L^{\prime} / 2\right)$ as follows:

$$
\theta=2 \Delta^{\prime} / L^{\prime}
$$

where the uppermost mid-span deflection could be determined from classic theory of structures, as given:

$$
\Delta^{\prime}=\frac{T g^{3}}{48 E I_{w a}},
$$

where $g$ is equivalent beam length illustrated in Figure 5(a) and $I_{w a}$ is the second moment of inertia along the unit length taken equal to $t_{w}^{3} / 12$, in which $t_{w}$ is thickness of the angle leg. Hence, the initial stiffness of web angles can be determined from the following relationship derived from Eqs. (5) to (7):

$$
K_{w a}=\frac{M_{1}}{\theta}=\frac{E L^{3} t_{w a}^{3}}{3 g^{3}} .
$$

Referring to Figure 4(a), the initial stiffness of the connection is composed of combined action of the flange-plates and the web angles. Therefore, the equivalent stiffness can be determined from rotational stiffness of the web angles and the flange-plates as follows:

$$
K_{\theta}=K_{w a}+2 K_{c}\left(\frac{d+t_{c}}{2}\right)^{2},
$$

where $d$ is beam depth, and $K_{\theta}$ is rotational stiffness of connection. Hence, the following relationship was derived for estimating the initial stiffness of the proposed connection:

$$
\begin{aligned}
K_{\theta}= & \frac{E I}{r} \frac{\left(d+t_{c}\right)^{2}}{2}\left\{\left(\frac{\pi^{2}-8}{2 \pi}\right) r^{2}\right. \\
& \left.+\frac{\pi}{2 \alpha A / I}(2+2 v+\alpha)\right\}^{-1}+\frac{E L^{3} t_{w a}^{3}}{3 g^{3}} .
\end{aligned}
$$

The inelastic stiffness of beam-to-column connections is usually explained as a coefficient of initial stiffness. Mofid et al. [14] considered four percent of elastic stiffness as the inelastic stiffness for semi-rigid flange end-plate connections. Likewise, in this paper, four percent of initial stiffness is considered as the inelastic stiffness.
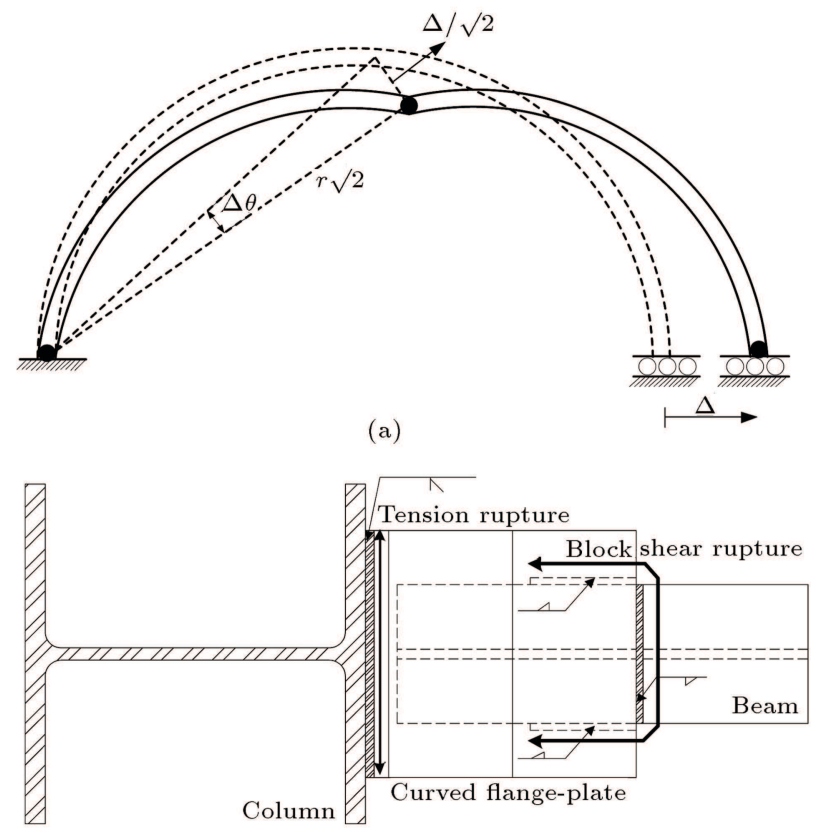

(b)

Figure 6. Failure modes of curved flange-plate: (a) Plastic failure in semi-circular portion of flange-plate; and (b) block shear and tension rupture.

\subsection{Ultimate moment}

Failure of semi-circular portion, block shear rupture, and rupture failure are the main failure modes of the flange-plate, which should be considered for evaluation of the ultimate moment. Figure 6(a) and (b) illustrates probable failure modes in the flange-plate. The formation of three plastic hinges in semi-circular portion results in failure of the flange-plate shown in Figure 6(a). Application of the principle of virtual work for this mechanism leads to the following relationship:

$$
P_{u 1} \Delta_{1}=4 M_{p} \Delta \theta,
$$

where $\Delta_{1}$ is end displacement of semi-circular portion shown in Figure 6(a), $M_{p}$ is plastic moment, $\Delta \theta$ is variation of plastic hinge rotations, and $P_{u 1}$ is the ultimate load transferred by beam flange which can be written as:

$$
P_{u 1}=\frac{M_{u 1}}{d+t_{c}},
$$

where $d$ is beam depth, $t_{c}$ is flange-plate thickness, and $M_{u 1}$ is the corresponding ultimate moment. Figure 6(a) shows deformed geometry of the semi-circular portion of flange-plate. As shown, variation of plastic hinge rotation can be expressed in terms of end displacement $\left(\Delta_{1}\right)$ and plate radius $(r)$ :

$$
\Delta \theta=\frac{\Delta_{1}}{2 r} .
$$

Therefore, the ultimate moment corresponding to this 
failure mode will be determined by replacing Eqs. (11) and (12) into Eq. (10) as follows:

$$
M_{u 1}=2 M_{p} \frac{\left(d+t_{c}\right)}{r} \text {. }
$$

Figure 6(b) shows block shear rupture of the flangeplate, which results from partial load transmission between the beam flange and the plate. Shear yielding or shear rupture along the beam longitudinal axis and tension rupture along the plate width make contribution to block shear strength. According to AISC 360-10 [20], the ultimate moment corresponding to the block shear rupture is determined from the following relationship:

$$
\begin{gathered}
M_{u 2}=\operatorname{Min}\left\{\left(0.6 F_{y} A_{g v}+F_{u} A_{n t}\right)\left(d+t_{c}\right),\right. \\
\left.\left(0.6 F_{u} A_{n v}+F_{u} A_{n t}\right)\left(d+t_{c}\right)\right\},
\end{gathered}
$$

where $A_{n v}$ and $A_{n t}$ are net areas subject to shear and tension, respectively, and $F_{u}$ is the ultimate stress.

Another possible failure mode is tension rupture of the flange-plate along the groove weld, which connects the plate to the column, as shown in Figure 6(b). This mechanism limits the ultimate moment to:

$$
M_{u 3}=F_{u} A_{n t}\left(d+t_{c}\right)
$$

where $A_{n t}$ is net area subjected to tension. Therefore, the ultimate moment of the connection is estimated from the minimum ultimate moment corresponding to the failure modes given by Eqs. (13) to (15), i.e.:

$$
\begin{aligned}
M_{u}= & \operatorname{Min}\left\{2 M_{p} \frac{\left(d+t_{c}\right)}{r},\left(0.6 F_{y} A_{g v}+F_{u} A_{n t}\right)\left(d+t_{c}\right),\right. \\
& \left.\left(0.6 F_{u} A_{n v}+F_{u} A_{n t}\right)\left(d+t_{c}\right), F_{u} A_{n t}\left(d+t_{c}\right)\right\} \cdot(16)
\end{aligned}
$$

\subsection{Ultimate rotation}

Preliminary assessment of the ultimate moment based on Eq. (16) reveals that in most of the cases, the plastic failure mechanism of the flange-plate is the dominant cause of failure. Thus, this failure mode was used for quantification of the ultimate rotation. Figure $7(\mathrm{a})$ shows a failure mechanism comprised of four linear parts and three plastic hinges, which was identified for end-plate connections by Beg et al. [21]. Figure 7(b) depicts the formation of three plastic hinges in the semi-circular portion of flange-plate. Since both mechanisms are identical, theoretical formulations suggested by Beg et al. [21] can be adopted. Hence, the ultimate displacement of each plastic hinge $\left(\Delta_{h}\right)$ will be determined from the following relationship [21]:

$$
\Delta_{h}=\varepsilon_{u} t_{c},
$$

where $t_{c}$ is plate thickness and $\varepsilon_{u}$ is the ultimate strain.

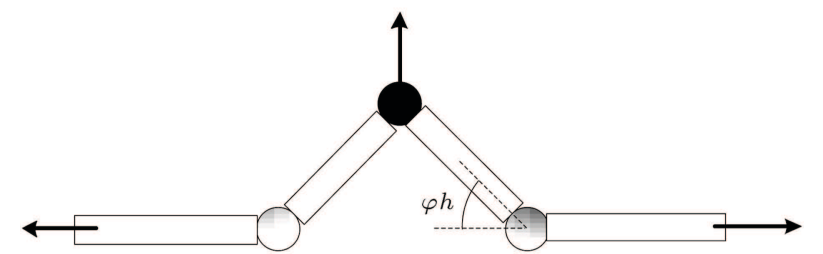

(a)

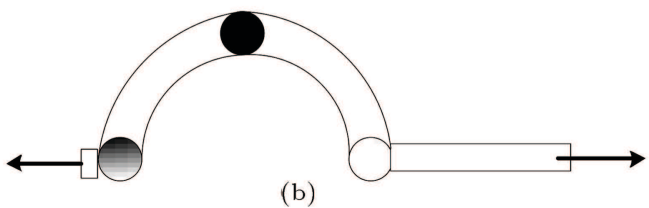

(b)

Figure 7. (a) Beg et al. [21] model. (b) Failure mechanism of flange-plate.

Furthermore, the sum of the ultimate displacement of plastic hinges can provide an estimation of the ultimate displacement, $\Delta_{u}$, as follows:

$$
\Delta_{u}=\varepsilon \Delta_{h}
$$

Division of the ultimate displacement by half of the beam depth, plus the plate thickness, gives an estimate of the ultimate rotation as follows:

$$
\theta_{u}=\frac{\Delta_{u}}{\left(d+t_{c}\right) / 2} .
$$

By combining the forgoing relationships, the ultimate rotation will be found from:

$$
\theta_{u}=\frac{6 \varepsilon_{u} t_{c}}{d+t_{c}} .
$$

\subsection{Yield moment and rotation}

In the preceding sections, theoretical-based relationships were suggested for the initial stiffness, the ultimate moment, and the ultimate rotation. Additionally, the inelastic stiffness was expressed as $4 \%$ of the initial stiffness. Therefore, the forgoing bilinear momentrotation model can be calibrated accordingly. Furthermore, yield moment and rotation can be explained in terms of the ultimate moment and rotation as well as elastic and inelastic stiffness as follows:

$$
\begin{aligned}
& M_{y}=\frac{K_{i}}{K_{i}-K_{p}}\left(M_{u}-K_{p} \theta_{u}\right), \\
& \theta_{y}=\frac{M_{u}-K_{p} \theta_{u}}{K_{i}-K_{p}} .
\end{aligned}
$$

\section{FE analyses}

\subsection{Specimens and analyses}

Eighteen curved flange-plate connections were designed based upon the result of the forgoing theoretical assessment. Table 1 presents geometric configuration of column, beam, and flange-plates. The conventional 
Table 1. Geometric properties of FE models (dimensions in millimeters).

\begin{tabular}{ccccccc}
\hline Model & Column & Beam & \multicolumn{5}{c}{ Flange-plate dimensions } \\
\cline { 5 - 7 } no. & section & section & Length & Width & Thickness & Radius \\
\hline 1801 & IPB400 & IPE180 & 70 & 130 & 9 & 30 \\
1802 & IPB400 & IPE180 & 70 & 130 & 12 & 30 \\
1803 & IPB400 & IPE180 & 70 & 130 & 9 & 40 \\
1804 & IPB400 & IPE180 & 70 & 130 & 12 & 40 \\
1805 & IPB400 & IPE180 & 70 & 130 & 9 & 50 \\
1806 & IPB400 & IPE180 & 70 & 130 & 12 & 50 \\
2201 & IPB400 & IPE220 & 70 & 150 & 9 & 30 \\
2202 & IPB400 & IPE220 & 70 & 150 & 12 & 30 \\
2203 & IPB400 & IPE220 & 70 & 150 & 9 & 40 \\
2204 & IPB400 & IPE220 & 70 & 150 & 12 & 40 \\
2205 & IPB400 & IPE220 & 70 & 150 & 9 & 50 \\
2206 & IPB400 & IPE220 & 70 & 150 & 12 & 50 \\
2701 & IPB400 & IPE270 & 70 & 175 & 9 & 30 \\
2702 & IPB400 & IPE270 & 70 & 175 & 12 & 30 \\
2703 & IPB400 & IPE270 & 70 & 175 & 9 & 40 \\
2704 & IPB400 & IPE270 & 70 & 175 & 12 & 40 \\
2705 & IPB400 & IPE270 & 70 & 175 & 9 & 50 \\
2706 & IPB400 & IPE270 & 70 & 175 & 12 & 50 \\
\hline
\end{tabular}

100-mm equal-legs angles, $100 \mathrm{~mm}$ in length, and $10 \mathrm{~mm}$ in thickness, were used for shear transmission between the beam and the column. It should be noted that specimens were designed such that plastic failure of semi-circular portion becomes dominant.

SUT-DAM [22] was used to develop nonlinear FE models for evaluation of connection performance subjected to pure bending. Eight-node hexahedral brick elements associated with reduced integration were used to discretize the models. Figure 8 shows discretized FE model. One half of the connection was simulated due to a plane of symmetry existing through the longitudinal axis of the beam [23]. Beam

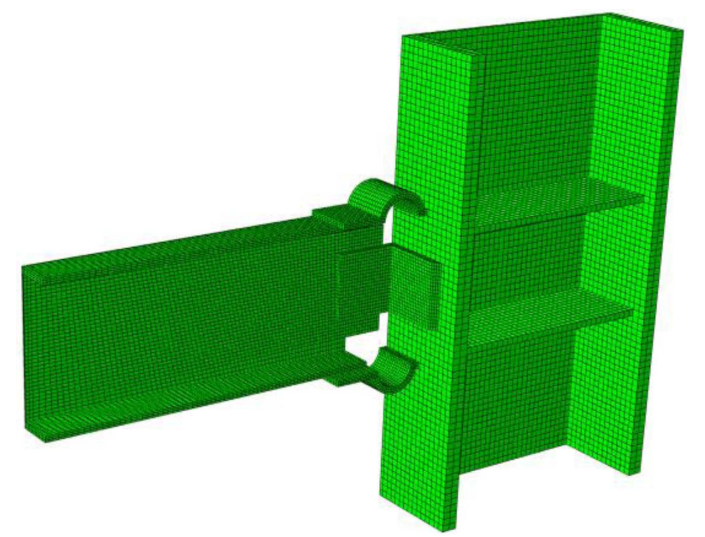

Figure 8. FE models discretized by 8 -node brick elements. nodes at the end of the beam were constrained to a reference point at which bending moment around the beam major axis was applied. Completely fixed boundary condition was assigned to the nodes located at both column ends. Surface-to-surface hard contact between the curved plates and the beam was considered in order to prevent surface penetration [23]. Groove and fillet welds were also simulated, which were tied to the related areas. It should be noted that the analyses were carried out statically, and the loading was controlled by the beam rotation. Furthermore, full Newton-Raphson method was employed to perform iterative static analyses.

Constitutive model shown in Figure 3, is composed of four linear segments suggested by MohamadiShooreh and Mofid [16]. According to the figure, the material exhibits a linear elastic behavior with a modulus of elasticity equal to $207 \mathrm{GPa}$, and the material remains elastic as long as the stress is lower than yield stress equal to $240 \mathrm{MPa}$. After yielding, the stress gradually increases on a slight gradient, $4.14 \mathrm{GPa}$, continues to the plastic strain $\left(\varepsilon_{p}\right)$ taken equal to $11 \varepsilon_{y}$, which will be equal to 0.0127 . Workhardening behavior extends to $370 \mathrm{MPa}$ and $120 \varepsilon_{y}$ as the ultimate stress and strain, respectively. Likewise, similar constitutive model was considered for weld metals with 330 and $415 \mathrm{MPa}$ as the yield and ultimate stresses, respectively [13]. It should be noted that the hardening behavior was introduced as isotropic. 

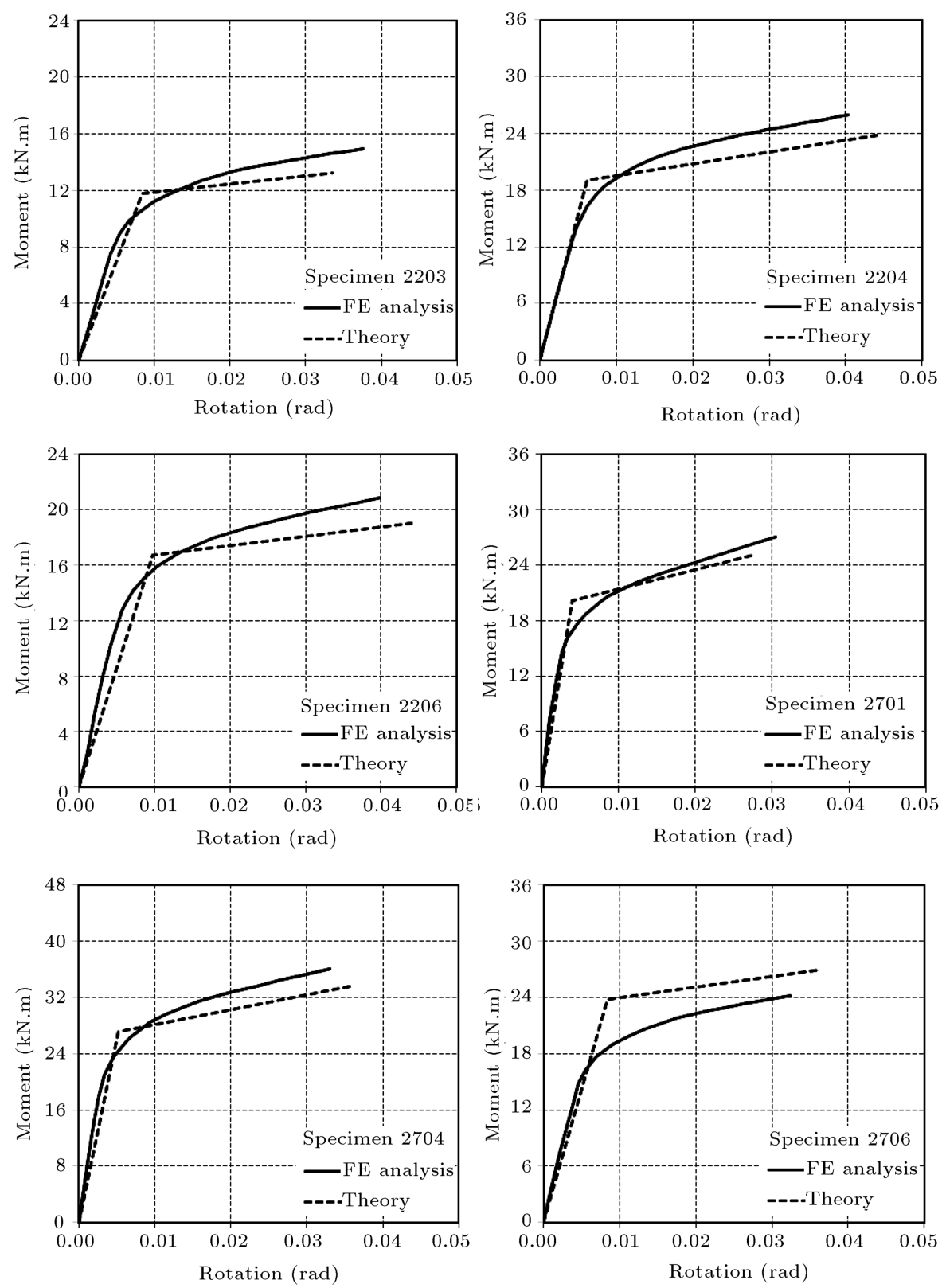

Figure 9. Moment rotation behavior of specimens.

\subsection{Verification}

Figure 9 draws a comparison between theoretical and analytical moment-rotation curves. FE analyses are in good agreement with theories. In Table 2, the results of theories and simulations are summarized, including initial stiffness, the ultimate moment, and the ultimate rotation. The estimated error for initial stiffness, the ultimate moment, and the ultimate rotation are obtained as well. The differences between the analyses and the theories are minor, which provide evidence for verification of simulations.

\subsection{Results and discussion}

Table 2 presents the results of $\mathrm{FE}$ analyses. An increase in flange-plate thickness leads to an increase in the initial stiffness and the ultimate moment as opposed to the radius that causes a reduction. Nevertheless, effects of thickness and radius of the flange-plate on the ultimate moment are rather negligible, as represented in Table 2. In addition, the ratio between the ultimate moment and the yield moment obtained from the FE analyses can be considered as an index for evaluation of ductility. This was also calculated and obtained in Table 2, indicating a ductility index about 7 on average. Furthermore, according to Table 2, an increase in the plate thickness increases the ductility index, and further increase of the radius reduces the ductility significantly.

Since Von-Mises stress does not depend on the stress direction, it could be considered as an appro- 
Table 2. Summary of analytical and theoretical results.

\begin{tabular}{|c|c|c|c|c|c|c|c|c|c|c|}
\hline \multirow{2}{*}{$\begin{array}{l}\text { Specimen } \\
\text { no. }\end{array}$} & \multirow{2}{*}{$\begin{array}{l}\text { Ductility } \\
\text { index }\end{array}$} & \multicolumn{3}{|c|}{$\begin{array}{c}\text { Initial stiffness } \\
(\mathrm{kN} . \mathrm{m} / \mathrm{rad})\end{array}$} & \multicolumn{3}{|c|}{$\begin{array}{c}\text { Ultimate moment } \\
(\mathrm{kN} . \mathrm{m})\end{array}$} & \multicolumn{3}{|c|}{$\begin{array}{c}\text { Ultimate rotation } \\
(\mathrm{rad})\end{array}$} \\
\hline & & Theory & FEM & Error (\%) & Theory & FEM & Error (\%) & Theory & FEM & Error (\%) \\
\hline 1801 & 9.05 & 1812.7 & 2105.7 & 13.9 & 12.60 & 14.20 & 12.7 & 0.0406 & 0.0443 & 9.3 \\
\hline 1802 & 14.56 & 4145.4 & 4532.7 & 8.5 & 22.80 & 25.40 & 11.4 & 0.0533 & 0.0486 & 8.7 \\
\hline 1803 & 5.75 & 824.8 & 1012.4 & 18.5 & 9.50 & 10.60 & 11.6 & 0.0406 & 0.0454 & 11.8 \\
\hline 1804 & 7.60 & 1868.5 & 2147.0 & 13.0 & 17.10 & 19.40 & 13.5 & 0.0533 & 0.0492 & 7.7 \\
\hline 1805 & 4.55 & 461.3 & 598.4 & 22.9 & 7.60 & 8.60 & 13.2 & 0.0406 & 0.0460 & 13.3 \\
\hline 1806 & 6.11 & 1010.9 & 1185.6 & 14.7 & 13.70 & 15.20 & 10.9 & 0.0533 & 0.0583 & 9.5 \\
\hline 2201 & 6.87 & 3022.1 & 3410.9 & 11.4 & 17.60 & 19.40 & 10.2 & 0.0335 & 0.0301 & 10.2 \\
\hline 2202 & 13.73 & 6935.7 & 7663.6 & 9.5 & 31.70 & 34.40 & 8.5 & 0.0441 & 0.0402 & 8.9 \\
\hline 2203 & 5.00 & 1348.5 & 1584.2 & 14.9 & 13.20 & 14.80 & 12.1 & 0.0335 & 0.0375 & 12.1 \\
\hline 2204 & 6.98 & 3099.9 & 2896.2 & 7.0 & 23.80 & 26.40 & 10.9 & 0.0441 & 0.0403 & 8.5 \\
\hline 2205 & 3.56 & 732.8 & 935.9 & 21.7 & 10.60 & 12.10 & 14.2 & 0.0335 & 0.0369 & 10.1 \\
\hline 2206 & 4.48 & 1655.1 & 1967.7 & 15.9 & 19.00 & 20.85 & 9.7 & 0.0441 & 0.0399 & 9.5 \\
\hline 2701 & 8.05 & 5182.2 & 5604.8 & 7.5 & 25.00 & 27.40 & 9.6 & 0.0275 & 0.0304 & 10.5 \\
\hline 2702 & 13.25 & 11904.7 & 13129.4 & 9.3 & 45.00 & 40.50 & 10.0 & 0.0363 & 0.0328 & 9.6 \\
\hline 2703 & 3.62 & 2284.1 & 2582.1 & 11.5 & 18.60 & 20.30 & 9.1 & 0.0275 & 0.0245 & 10.7 \\
\hline 2704 & 6.62 & 5292.8 & 5801.9 & 8.8 & 33.20 & 36.12 & 8.8 & 0.0363 & 0.0330 & 8.9 \\
\hline 2705 & 3.06 & 1217.8 & 1451.7 & 16.1 & 15.00 & 16.90 & 12.7 & 0.0275 & 0.0302 & 9.9 \\
\hline 2706 & 4.09 & 2802.3 & 3149.5 & 11.0 & 27.00 & 24.17 & 10.5 & 0.0363 & 0.0324 & 10.6 \\
\hline Average & 7.05 & - & - & 13.1 & - & - & 11.09 & - & - & 9.99 \\
\hline
\end{tabular}

priate measure for evaluation of stress concentration. Figure 10(a) shows the Von-Mises stress contours on the deformed shape. Stress concentration at the both ends of the semi-circular portion of the flangeplate is more severe. Fillet welds that connect the web-angles to the column flange are also exposed to high stress concentration. However, prediction of rupture under monotonic loadings can be predicted by identification of high strain zones [24]. Figure 10(b) indicates deformed shape of the connection along with equivalent plastic strain contours. As shown, plastic strain accumulates on the three plastic hinges, which confirms the formation of three plastic hinges discussed earlier. In general, high strain zones are the most probable locations to experience rupture. Hence, the flange-plate is expected to experience rupture at the both ends of the semi-circular portion of the flangeplate.

\section{Design procedure}

In the preceding sections, the overall behavior is investigated and discussed extensively. And, some recommendations are made for the design of such connections. Nevertheless, a design flow chart seems to be helpful. Hence, we established a flow chart in order to design welded curved flange plate connections shown in Figure 11. The flow chart starts with specification of the ultimate moment, the ultimate rotation, and the beam depth may be used for calculation of the plate thickness based on Eq. (17). Another parameter that should be chosen wisely is the radius of semi-circular portion, which is recommended to be considered within the 30-50 mm interval. Subsequently, Eq. (13) may be used for calculation of the plate width, provided that the width does not exceed the column width; otherwise, we should modify our assumption for the radius. After the successful calculation of the width, the ultimate moment corresponding to the block shear rupture and to the tension rupture, $M_{u 2}$ and $M_{u 3}$ should be determined in order to ensure that the three-point plastic hinge mechanism is the dominant case of failure. As an advantage, it can be highlighted that application of this diagram prevents less ductile failure modes. In other words, improvement of ductility and energy dissipation capacity, as well as semi-rigid behavior, makes curved welded flange-plate connections promising.

\section{Conclusion}

Curved welded flange-plate beam-to-column connections were introduced and investigated analytically under monotonic loading. Theoretical relationships were established for initial stiffness, inelastic stiff- 


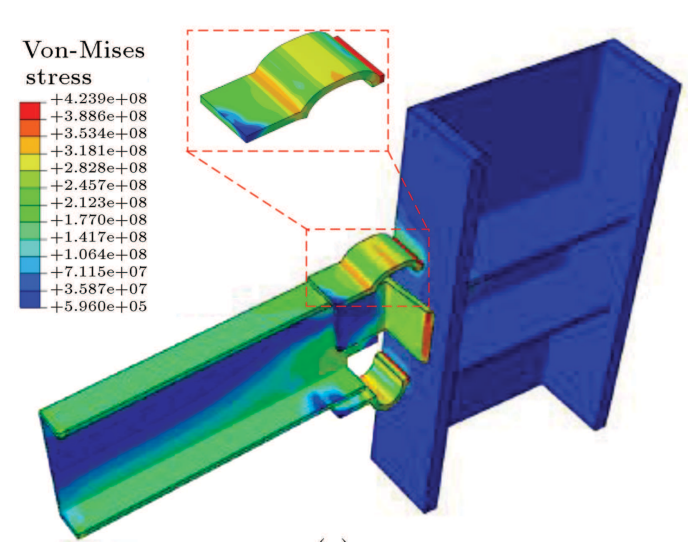

(a)

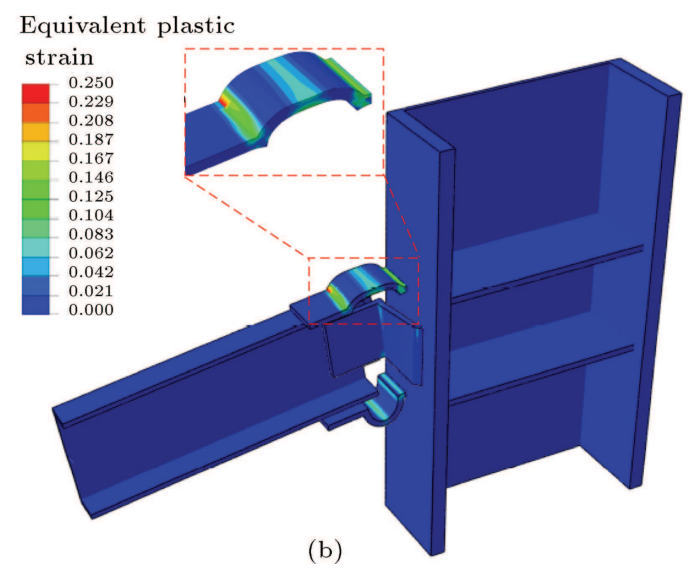

Figure 10. Curved flange-plate connection subject to pure bending: (a) Von-Mises stress contours; and (b) equivalent plastic strain contours.

ness, the ultimate moment, and the ultimate rotation. The concept of curved flange-plate was proved to be promising and should be the subject of further studies. In other words, the present paper paves the way for conducting experiments and further numerical studies. Furthermore, the following conclusions can be summarized from the results of this paper:

- Three plastic hinges formed failure mechanism of the curved flange-plate. This mechanism draws an important distinction between the proposed connections compared to the conventional flange-plate connections;

- Application of semi-circular flange-plate can significantly improve energy dissipation capacity as well as the ductility;

- A bilinear moment-rotation model was developed based on the results of theoretical approach. This model is adopted for verification of FE analyses;

- Theoretical moment-rotation curves are in close agreement with analyses;

- Application of the proposed flow chart prevents less ductile failure cases and makes the favorable plastic failure the dominant case.

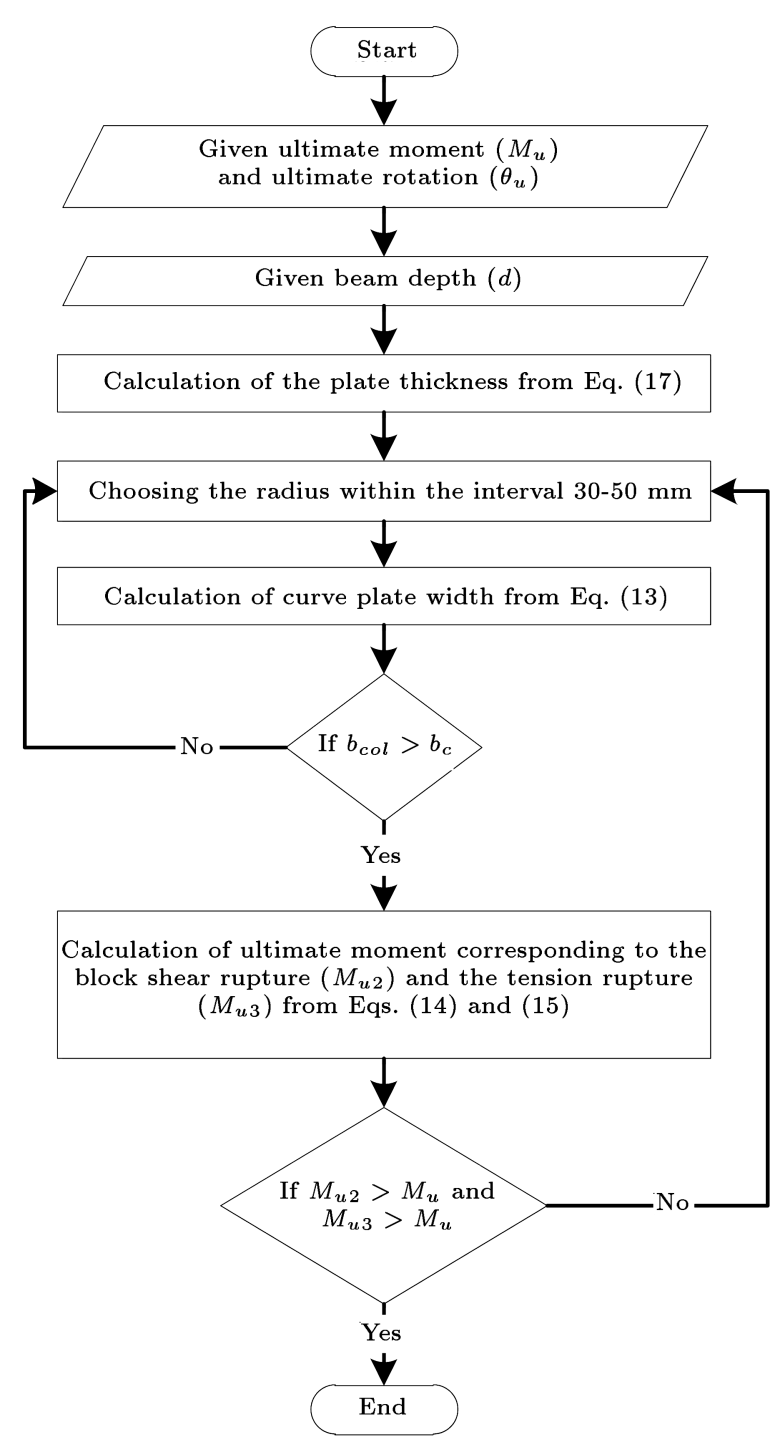

Figure 11. Design diagram for curved welded flange plate connections.

\section{Nomenclature}

A Cross sectional area

$A_{g v} \quad$ Gross area subject to shear

$A_{n v} \quad$ Net area subject to shear

$A_{n t} \quad$ Net area subject to tension

E Modulus of elasticity

$F_{y} \quad$ Yield stress

$F_{u} \quad$ The ultimate stress

$G \quad$ Shear modulus

I The second moment of inertia

$I_{w a} \quad$ The second moment of inertia along unit length of angle

$K_{c} \quad$ Elastic stiffness of curved-plate

$K_{w a} \quad$ Initial stiffness of web angles

$K_{\theta} \quad$ Rotational stiffness 
$K_{i} \quad$ Initial stiffness

$K_{p} \quad$ Inelastic stiffness

$L^{\prime} \quad$ Angle length

$M(r) \quad$ Internal bending moment

$M_{0} \quad$ End moment of curved-plate

$M_{1} \quad$ Bending moment of web angle

$M_{p} \quad$ Plastic moment

$M_{y} \quad$ Yield moment of connection

$M_{u i} \quad$ The ultimate moment corresponding to failure modes

$M_{u} \quad$ The ultimate moment of connection

$P(r) \quad$ Internal axial force

$P_{0} \quad$ Force applied at the end of curved-plate

$P_{u 1} \quad$ The ultimate load transferred from beam flange

$T \quad$ Load applied from beam to web angles

$V(r) \quad$ Shear force

$b_{c} \quad$ Width of curved flange-plate

$b_{\text {col }} \quad$ Flange width of column

d Beam depth

$g \quad$ Equivalent beam length illustrated

$r \quad$ Radius of curved-plate

$t_{w} \quad$ Thickness of angle leg

$t_{c} \quad$ Plate thickness

$\Pi \quad$ Total potential energy

$\alpha \quad$ Sectorial shear coefficient

$v \quad$ Poisson's ratio

$\varepsilon_{u} \quad$ The ultimate strain of material

$\Delta_{0} \quad$ Displacement of curved-plate

$\Delta^{\prime} \quad$ The uppermost mid-span deflection of angle

$\Delta_{1} \quad$ End displacement of semi-circular portion

$\Delta_{h} \quad$ The ultimate displacement of plastic hinge

$\Delta_{u} \quad$ Semi-circular ultimate displacement

$\theta \quad$ Rotation of angle

$\theta_{u} \quad$ The ultimate rotation of connection

$\theta_{y} \quad$ Yield rotation of connection

$\Delta \theta \quad$ Variation of plastic hinge rotations

\section{References}

1. Astaneh, A., Nader, M.N. and Malik, L. "Cyclic behavior of double angle connections", J. Struct. Eng. ASCE, 115(5), pp. 1101-1118 (1989). DOI: 10.1061/(ASCE)0733-9445(1989)115:5(1101)

2. Elghazouli, A.Y. "Ductility of frames with semi-rigid connections", 11th World. Conf. on Earthquake Engrg., Acapulco, Mexico (1996).
3. Popov, E.P. and Bertero, V.V. "Cyclic loading of steel beams and connections", J. Struct. Div. ASCE, 99(6), pp. 1189-1204 (1973). DOI: 10.1061/JSDEAG.0003329

4. Youssef-Agha, W., Aktan, H.M. and Olowokere, O.D. "Seismic response of low-rise steel frames", $J$. Struct. Eng. ASCE, 115(3), pp. 594-607 (1989). DOI: 10.1061/(ASCE)0733-9445(1989)115:3(594)

5. Kukreti, A.R., Murray, T.M. and Ghassemieh, M. "Finite element modeling of large capacity stiffened steel tee-hanger connections", Comput. Struct., 32(2), pp. 409-422 (1989). DOI: 10.1016/0045-7949(89)900527

6. Kukreti, A.R. and Abolmaali, A.S. "Moment-rotation hysteresis behavior of top and seat angle steel frame connections", J. Struct. Eng. ASCE, 125(8), pp. 810-820 (1999). DOI: 10.1061/(ASCE)07339445(1999)125:8(810)

7. Mohammadi-Shoreh, M.R. and Mofid, M. "Basic issues in the analytical simulation of unstiffened extended end plate connection", Sci. Iran., 11(4), pp. 302-311 (2004).

8. Lui, E.M. and Chen, W.F. "Steel frame analysis with flexible joints", J. Constr. Steel Res., 8, pp. 161-202 (1987). DOI: $10.1016 / 0143-974 X(87) 90058-7$

9. Khonsari, S.V., England, G.L., Shahsavar-Gargari, M. and Parvinnia, S.M.H. "Performance of an innovative beam-to-column connection under cyclic flexural loading”, 14WCEE, pp. 12-17 (2008).

10. Leon, R.T., DesRoches, R., Ocel, J. and Hess, G. "Innovative beam column connections using shape memory alloys", 8th Annual International Symposium on Smart Structures and Materials, pp. 227-237, International Society for Optics and Photonics (2001).

11. Comeliau, L., Demonceau, J.F. and Jaspart, J.P. "Innovative bolted beam-to-column joints for seismic resistant building frames", In Connection VII Proceedings (2012).

12. Yang, J.G. and Lee, G.Y. "Analytical models for the initial stiffness and ultimate moment of a double angle connection", Eng. Struct., 29(4), pp. 542-551 (2007). DOI: $10.1007 / B F 03249494$

13. Abolmaali, A., Matthys, J.H., Farooqi, M. and Choi, Y. "Development of moment-rotation model equations for flush end-plate connections", J. Constr. Steel Res., 61(12), pp. 1595-1612 (2005). DOI: 10.1016/j.jcsr.2005.05.004

14. Mofid, M., Mohammadi, M.R.S. and McCabe, S.L. "Analytical approach on endplate connection: Ultimate and yielding moment", J. Struct. Eng. ASCE, 131(3), pp. 449-456 (2005). DOI: 10.1061/(ASCE) 0733-9445(2005)131:3(449)

15. Lee, S.S. and Moon, T.S. "Moment-rotation model of semi-rigid connections with angles", Eng. Struct., 24(2), pp. 227-237 (2002). DOI: 10.1016/S0141-0296 (01)00066-9 
16. Mohamadi-Shooreh, M.R. and Mofid, M. "Parametric analyses on the initial stiffness of flush end-plate splice connections using FEM", J. Constr. Steel Res., 64(10), pp. 1129-1141 (2008). DOI: 10.1016/j.jcsr.2007.09.010

17. Mohamadi-Shoore, M.R. and Mofid, M. "New modeling for moment-rotation behavior of bolted endplate connections", Sci. Iran., 18(4), pp. 827-834 (2011). DOI: $10.1016 /$ j.scient.2011.07.015

18. Tall, L,. Structural Steel Design, Second Edition, Ronald Press Company, New York (1974).

19. Kishi, N. and Chen, W.F. "Moment-rotation relations of semi-rigid connections with angles", J. Struct. Eng. ASCE, 116(7), pp. 1813-1834 (1990). DOI: 10.1061/(ASCE)0733-9445(1990)116:7(1813)

20. AISC Committee, Specification for Structural Steel Buildings (ANSI/AISC 360-10), American Institute of Steel Construction, Chicago-Illinois (2010).

21. Beg, D., Zupančič, E. and Vayas, I. "On the rotation capacity of moment connections", J. Constr. Steel Res., 60(3), pp. 601-620 (2004). DOI: 10.1016/S0143974X(03)00132-9

22. Khoei, A.R., Gharehbaghi, S.A., Azami, A.R. and Tabarraie, A.R. "SUT-DAM: an integrated software environment for multi-disciplinary geotechnical engineering", Adv. Eng. Softw., 37(11), pp. 728-753 (2006). DOI: $10.1016 /$ j.advengsoft.2006.03.001

23. Mohamadi-Shooreh, M.R. and Mofid, M. "Prediction of the yielding moment of flush endplate splice connections using finite element modeling", Sci. Iran., 20(2), pp. 270-277 (2013). DOI: 10.1016/j.scient.2012.12.026

24. Myers, A.T., Kanvinde, A.M., and Deierlein, G.G. "Calibration of the SMCS criterion for ductile fracture in steels: specimen size dependence and parameter assessment", J. Eng. Mech. ASCE, 136(11), pp. 1401-1410 (2010). DOI: 10.1061/(ASCE)EM.19437889.0000178

\section{Biographies}

Yousef Ghafari received his BSc and MSc degrees from Sharif University of Technology in 2011 and 2013, respectively. At present, he is pursuing education as a $\mathrm{PhD}$ candidate at Sharif University of Technology. His current research is focused on design and behavior of steel beam-to-column connections.

Massood Mofid is a Professor of Structural and Earthquake Engineering in Sharif University of Technology, Tehran, Iran .

Omid Sedehi earned his BSc and MSc degrees from Isfahan University of Technology and Sharif University Technology in 2011 and 2013, respectively. At present, he is a PhD candidate at Sharif University of Technology. 